\title{
Organismos competentes para administrar determinados bienes nacionales de uso público: caminos públicos, vías urbanas y el subsuelo de un cauce de río y estero**.
}

Managing agencies for certain property use national public: public roads, underground urban and way of underground river or stream

\section{Resumen}

El presente artículo analiza la administración de determinados bienes nacionales de uso público. En concreto, tiene como objeto determinar cuál es el Organismo competente para administrar los caminos públicos, las vías urbanas y el subsuelo de cauce de río o estero. Para ilustrar lo anterior, hemos escogido, como casos a examinar, la instalación de atraviesos, paralelismos y acueductos en el subsuelo de cauces de ríos o esteros, ya que suele no existir claridad respecto de cuál entidad es la competente para autorizar su instalación, ya sea mediante un permiso o una concesión.

${ }^{*}$ Abogado. Licenciado en Ciencias Jurídicas $y$ Sociales por la Universidad de Chile.

Ayudante Facultad de Derecho de la Universidad de Chile. Abogado, Área Cumplimiento de Mercado Superintendencia de Valores y Seguros.

**Artículo recibido el 10 de Mayo de 2013 $y$ aceptado para su publicación el 7 de Junio de 2013.

\section{Palabras claves}

Dominio público, Bien nacional de uso público, administración de bienes públicos, bienes fiscales.

\section{Abstract}

This article analyzes the administration of certain national assets for public use. In particular, it aims to determine the competent organism to manage public roads, urban roads and the underground river or stream. To illustrate this, we have chosen, as cases to examine, the installation of crossing paths and parallelisms and aqueducts 
in underground rivers or streams, because often there is absence of clarity regarding which entity is responsible for authorizing the said installations, by permit or concession.

\section{Key Words}

Public domain, national asset of public use, public asset administration, fiscal assets

\section{Bienes Nacionales de uso público (bienes públicos) vs. Bienes fiscales (bienes del estado).}

Nuestra Constitución garantiza como regla general, de conformidad con el artículo 19 número 23, la libertad para adquirir el dominio de toda clase de bienes, vale decir, dicho "(...) precepto regula el derecho "a la propiedad" ${ }^{1}$. Sin embargo, este derecho fundamental a la "(...) libre apropiabilidad del dominio de los bienes (...)" 2 , contiene dos excepciones: (i) aquellos bienes que la naturaleza ha hecho comunes a todos los hombres; y (ii) aquellos bienes que deban pertenecer a la Nación toda y la ley lo declare así. Al respecto, tanto la reciente jurisprudencia constitucional $^{3}$ como parte de la doctrina ${ }^{4}$ sostienen que la primera hipótesis bienes que la naturaleza ha hecho comunes a todos los hombres- correspondería a o cosas comunes ${ }^{5}$ y por ende bienes inapropiables, mientras que la segunda categoría correspondería a cosas públicas también conocidas como bienes nacionales ${ }^{6}$. Sobre el particular, cabe hacer presente que la razón de por qué los primeros son definidos como comunes a todos los hombres, estriba en que "los ordenamientos jurídicos de los distintos países, junto al Derecho Internacional, [los] consideran como espacios ajenos a toda soberanía estatal"7. En efecto, parte de la doctrina sostiene que "a lo sumo podría hablarse de una propiedad común" 8 , por lo que dichas cosas escapan incluso al dominio del Estado?.

$\mathrm{Al}$ respecto, el artículo 589 del Código Civil define en su inciso primero a los bienes nacionales como "aquellos cuyo dominio pertenece a la nación toda". No obstante, debemos precisar que los bienes nacionales (segunda hipótesis) no deben confun-

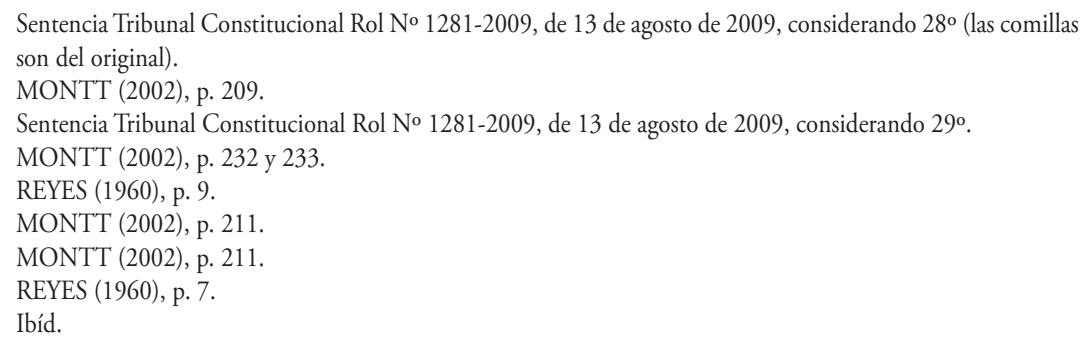


dirse con los bienes inapropiables ${ }^{10}$ (primera hipótesis), ya que sobre estos últimos "no se puede constituir dominio [y] (...) nuestro Código Civil les denomina cosas comunes a todos los hombres" ${ }^{11}$, tales como el alta mar $^{12}$ y el espacio ultraterrestre ${ }^{13}$. En efecto, se ha entendido que la razón de por qué son definidos como comunes a todos los hombres, estriba en que "los ordenamientos jurídicos de los distintos países, junto al Derecho Internacional, [los] consideran como espacios ajenos a toda soberanía estatal" 14 .

Pues bien, de conformidad con los incisos segundo y final del artículo 589 del Código Civil, los bienes nacionales pueden ser clasificados como (i) bienes nacionales de uso público o bienes públicos; y (ii) bienes fiscales o bienes del Estado. Los primeros son definidos como aquellos cuyo "uso pertenece a todos los habitantes de la nación, como el de calles, plazas, puentes y caminos, el mar adyacente y sus playas" 15 , como también el espectro radioeléctrico ${ }^{16}$. Por su parte, los bienes fiscales o bienes del Estado consisten en aquellos bienes nacionales "cuyo uso no pertenece a los habitantes" ${ }^{17}$, ya que éstos "constituyen el patrimonio privado del Estado, que pertenecen al Estado en cuanto este es persona de Derecho Privado" ${ }^{18}$. Un ejemplo de bien fiscal sería un edificio comprado por el Estado para albergar las oficinas de algún Ministerio.

Por su parte, una de las características que presentan los bienes nacionales de uso público es que "son incomerciables, [ya que] por su destino están fuera del comercio"19. Además, su administración "queda encargada a distintas autoridades, según su naturaleza: Municipalidades, reparticiones del Ministerio de Obras Públicas, Fuerzas Armadas, División de Bienes Nacionales del Ministerio de Bienes Nacionales" ${ }^{20}$. Así las cosas, y dependiendo del bien de uso público en cuestión, la autoridad que se encuentra legalmente habilitada para administrarlo "(...) puede otorgar a particulares "permisos" y "concesiones" sobre ellos" 21 . En el presente artículo, abordaremos la administración de los siguientes bienes nacionales de uso público, a saber: los caminos públicos y las vías urbanas, junto con el subsuelo del cauce de ríos o esteros.

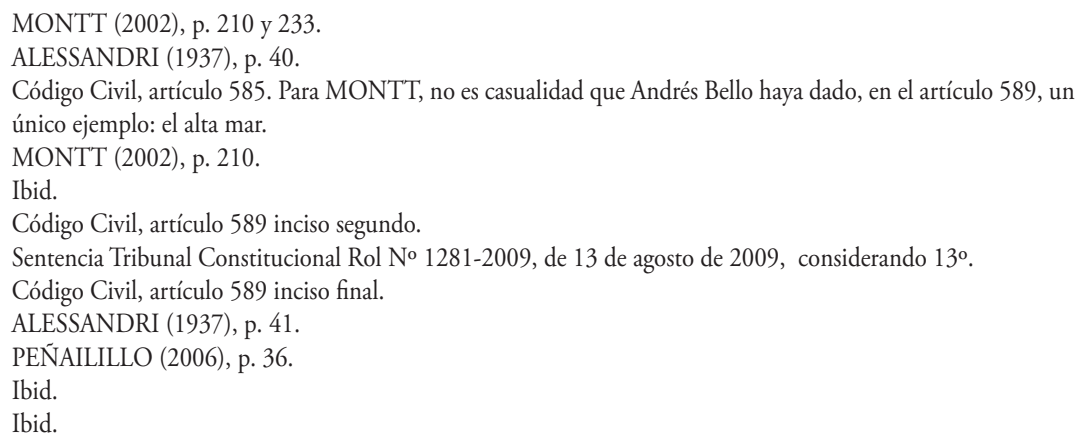




\section{Importancia de distinguir si nos encontramos ante un área rural o urbana para efectos de definir si la vía corresponde a un camino público o una vía urbana.}

Como se explicará, es de suma importancia distinguir si nos encontramos en un área rural o urbana para efectos de determinar si estamos en presencia de un camino público o una vía urbana.

La Ordenanza General de Urbanismo y Construcciones (la "OGUC") define en su artículo 1.1.2. al área urbana como la "superficie del territorio ubicada al interior del límite urbano, destinada al desarrollo armónico de los centros poblados y sus actividades existentes y proyectadas por el instrumento de planificación territorial”. En dicho artículo, la OGUC también define al área rural como el "territorio ubicado fuera del límite urbano". Al respecto, la Ley General de Urbanismo y Construcciones (la "LGUC") define al límite urbano en su artículo 52, en el siguiente sentido: "se entenderá por límite urbano, para los efectos de la presente ley y de la Ley Orgánica de Municipalidades, la línea imaginaria que delimita las áreas urbanas y las de extensión urbana que conforman los centros poblados, diferenciándolos del resto de la comuna”. En este sentido, y en relación con el ámbito de acción de la Planificación Urbana Intercomunal, misma que tiene por objeto regular el desarrollo físico de las áreas urbanas y rurales de las comunas, la OGUC advierte en su artículo 2.1.7 que le corresponderá inicialmente al Plan Regulador Intercomunal, dentro del área urbana, "la definición de los límites de extensión urbana, para los efectos de diferenciar el área urbana del resto del territorio, que se denominará área rural”. Asimismo, y en relación con la Planificación Urbana Comunal, la OGUC dispone en el número 3 de su artículo 2.1.10 que será la Municipalidad respectiva el único organismo facultado para definir "el límite urbano de sus centros poblados", tarea que debe concretar en su Ordenanza Local.

Así, la Ordenanza del Plan Regulador Metropolitano de Santiago (el "PRMS”) define en su artículo 2.2.1 al Área Urbana Metropolitana como "aquel territorio circunscrito por el Límite de Extensión Urbana y que por su capacidad, se destina a acoger el crecimiento de la población urbana y sus actividades, estimada al ańo 2020". Asimismo, los planos del PRMS RM-PRM-92-1A1 y RM-PRM-92-1A grafican la ubicación del límite de extensión urbana de Santiago. Por ende, sólo cabe concluir que el límite urbano coincide con el límite de la zona de extensión urbana, ya que la zona urbana comprende a la zona de extensión urbana, estando esta última dentro de la primera.

En este sentido, la División de Desarrollo Urbano del Ministerio de Vivienda y Urbanismo (la "DDU”)22, a través de su Circular No 0368 del 04 de junio de 2009 (DDUEspecífica No 10/2009), advirtió que "la Ley General de Urbanismo y Construcciones

22 En virtud del artículo 4 de la LGUC, a la División de Desarrollo Urbano del Ministerio de Vivienda y Urbanismo le corresponde impartir instrucciones para la aplicación de las disposiciones de la LGUC y de su Ordenanza, mediante circulares. 
divide el territorio en sólo dos áreas, área urbana y área rural, no existiendo, para estos efectos, otro tipo de división del territorio y por lo mismo los planes reguladores intercomunales no tienen competencia para establecerlas" 23 . De este modo, "el área urbana corresponde al territorio inserto dentro de un límite urbano y este último incluye en su interior al límite de extensión urbana. Por su parte, el área rural corresponde al resto del territorio de la comuna situado fuera del límite urbano (...). Conforme a lo anterior, las áreas urbanas y de extensión urbana se encuentran al interior del límite urbano, y el área rural se encuentra fuera de dicho límite urbano, pudiendo éste pertenecer o no a un territorio regulado por un plan regulador intercomunal o metropolitano"24 (el énfasis es nuestro).

En consecuencia, en virtud de la LGUC, la OGUC y la interpretación de la DDU, toda área ubicada fuera del límite urbano es "rural", pudiendo esta última encontrarse regulada (en todo o en parte) o no por un plan regulador intercomunal o metropolitano ${ }^{25}$. Distinguir si nos encontramos ante un área rural o urbana, determinará si una vía se encuentra bajo la administración del Ministerio de Obras Públicas o de una municipalidad, cuestión que se explicará a continuación.

\section{Competencia del MOP para administrar las fajas de los caminos públicos.}

El DFL 850 de 1997, que fija el texto refundido, coordinado y sistematizado de la LOC MOP y de la Ley de Caminos (el “DFL 850/1997”), en su artículo 18 inciso 7 le otorga competencia a la Dirección de Vialidad del Ministerio de Obras Públicas (la "Dirección de Vialidad" y el "MOP") para "la aplicación del Título III de esta ley sobre caminos públicos”. En efecto, la Contraloría General de la República, en un dictamen de 2007, reiteró que la Dirección de Vialidad está encargada de la administración, tuición o guarda de los caminos públicos del país ${ }^{26}$.

Así, el Título III del DFL 850/1997 trata “De los Caminos Públicos" (artículos 24 a 53) y en su artículo 24 precisa cómo una vía pasa a tener la naturaleza de camino público, definiendo tres alternativas para ello. La primera alternativa -y, por lo demás, la más común- dispone que son caminos públicos (i) "las vías de comunicación terrestres destinadas al libre tránsito, situadas fuera de los límites urbanos de una población y cuyas fajas son bienes nacionales de uso público"27 (el énfasis es nuestro). Asimismo, son caminos públicos (ii) "las calles o avenidas [urbanas] que unan caminos públicos, declaradas como tales por decreto supremo"28 (el énfasis es nuestro). Finalmente, son

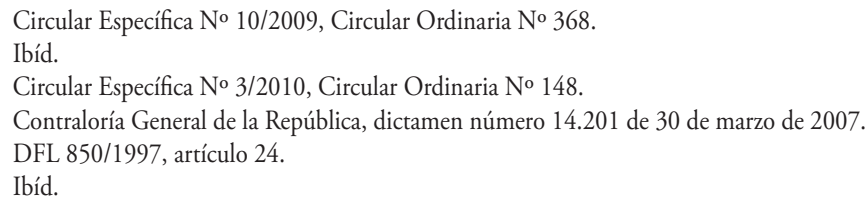


caminos públicos (iii) "las vías señaladas como caminos públicos en los planos oficiales de los terrenos transferidos por el Estado a particulares, incluidos los concedidos a indígenas" (el énfasis es nuestro).

De este modo, y tomando en cuenta que toda área ubicada fuera del límite urbano corresponde a un área rural, son caminos públicos todas las vías ubicadas en las áreas rurales. A contrario sensu, y por regla general, tienen la naturaleza de vías urbanas todas las calles o avenidas ubicadas en un área urbana, vale decir, ubicada dentro del límite urbano o de extensión urbana. Sin embargo, hacen excepción a dicha regla general aquellas vías que, ubicadas dentro de un área urbana, por decreto supremo han sido "afectadas" con la calidad de caminos públicos, atendido que unen caminos públicos. La lógica de lo anterior es clara y no es otra que dar continuidad a un camino público, ya que no sería razonable que una vía, manteniendo su mismo tamaño y características, sea en un sector "camino público" y en otro "vía urbana”. En caso contrario, la Dirección de Vialidad sólo sería competente en aquellos sectores de la vía que se encuentren en áreas rurales, mas no en aquellos emplazados dentro del límite urbano (área urbana).

Podemos ejemplificar lo anterior, con las otrora vías urbanas M7P y T22P del PRMS, que corresponden en la actualidad a la extensión de la Autopista Costanera Norte ${ }^{29}$, desde Av. Américo Vespucio hacia la Ruta 68 Camino a Valparaíso. Es del caso señalar, que si bien las vías M7P y T22P estaban previstas en el PRMS de 1994 como vías urbanas, pasaron a ser caminos públicos a fines de 2003, una vez que fueron afectadas como tales por el Decreto Supremo No 1.403 del 28 de noviembre de 2003, publicado en el Diario Oficial el 19 de enero de 2004. En consecuencia, luego de la entrada en vigencia de este Decreto Supremo, las vías urbanas M7P y T22P, proyectadas ambas en el PRMS, pasaron a tener la calidad de caminos públicos bajo la competencia de la Dirección de Vialidad del MOP.

Finalmente, y en relación con los caminos públicos señalados en los planos oficiales de los terrenos transferidos por el Estado a particulares, estimamos que la importancia de dicha categoría radica en definir, en la misma ley, que dichos caminos serán públicos y no privados o de uso particular. Lo anterior, ya que en caso de no contemplar dicha definición el DFL/1997, y luego de transferirse un terreno a un particular (que por lo general son alejados de núcleos urbanos y, por ende, se emplazarían en áreas rurales), podría interpretarse que las vías ubicadas "dentro" del terreno cedido a particulares, por el hecho de ser éste ahora privado, ellas también lo serían.

Por su parte, el artículo 41 de la DFL 850/1997 menciona que "las fajas de los caminos públicos son de competencia de la Dirección de Vialidad y están destinados principalmente al uso de las obras del camino respectivo" (el énfasis es nuestro). Su inciso tercero continúa indicando que, "sin perjuicio de sus atribuciones, la Dirección de Vialidad podrá autorizar, en la forma y condiciones que ella determine, con cargo a sus respectivos propietarios, y previo pago de los derechos correspondientes, la colocación 
de cañerías de agua potable y de desagüe; las obras sanitarias; los canales de riego; las tuberías o ductos para la conducción de líquidos, gases o cables; las postaciones con alambrado telefónico, telegráfico o de transmisión de energía eléctrica o fibra óptica y, en general, cualquier instalación que ocupe los caminos públicos y sus respectivas fajas de dominio público u otras obras viales regidas por esta ley (...). Dichas autorizaciones deberán otorgarse, a menos que se opongan al uso de los caminos públicos, sus fajas adyacentes, pasos a nivel y obras de arte, o al uso de túneles o puentes; no afecten la estabilidad de las obras, la seguridad del tránsito o el desarrollo futuro de las vías; no obstruyan o alteren el paso de las aguas; no produzcan contaminación ni alteración significativa, en cuanto a magnitud o duración, del valor paisajístico o turístico de una zona; y sea posible su otorgamiento, teniendo en cuenta las instalaciones anexas ya autorizadas" (el énfasis es nuestro).

$\mathrm{Al}$ respecto, estimamos que dichas fajas corresponderían al concepto de "faja fiscal", independiente que el DFL/1997 no las defina de ese modo. A esta conclusión ha llegado la Contraloría General de la República, entidad que en relación con el artículo 41 del DFL 850/199730 ha señalado “(...) que el objetivo de Ley $\mathrm{N}^{\circ} 19.474$ [actual DFL 850/1997] es que todo usuario de la faja fiscal quede afecto a la normativa del artículo 41, sin excepción de ninguna especie; que los derechos por la ocupación de la faja son contraprestaciones, que se basan en el costo de la inspección y control de la infraestructura o espacios viales afectados por las instalaciones ajenas al camino; que a la Dirección de Vialidad corresponde autorizar la colocación de las diversas instalaciones (...), con el fundamento de las necesidades del camino (...)"31 (el énfasis es nuestro). Luego, según la interpretación que hace la Contraloría General de la República del artículo 41 del DFL 850/1997, a la Dirección de Vialidad le corresponde la administración de "la faja fiscal en comento [, la que] está sujeta a un régimen jurídico especial diverso del que se aplica a los particulares, el cual entrega la titularidad de dicho terreno a esa Dirección" ${ }^{2}$.

Por su parte, el artículo 39 del DFL 850/1997, para regular esta materia, esgrime sólo el vocablo faja: "Se prohíbe a los dueños de los predios colindantes con los caminos públicos nacionales, ocupar las fajas de 35 metros medidos a cada lado de los cierros actuales [de la faja] o los que se ejecuten en variantes o caminos nuevos nacionales, con construcciones de tipo definitivo que en el futuro perjudiquen su ensanche". Con todo, en la discusión acerca de la modificación a la otrora ley No 19.474 (actual DFL 850/1997), el Senado se refirió al concepto de "faja" o "faja del camino" como "faja fiscal" ${ }^{33}$. Lo anterior, corrobora que la Faja Fiscal sería la "faja" a que se refiere el DFL 850/1997.

30 DFL 850/1997, artículo 41: "las fajas de los caminos públicos son de competencia de la Dirección de Vialidad y están destinados principalmente al uso de las obras del camino respectivo".

Contraloría General de la República, dictamen No 5.230, del 11 de febrero del 2000.

Contraloría General de la República, dictamen No 18.020, del 06 de mayo del 2003.

3 Senado, Sesión 8a, Ordinaria, del 18 de junio de 1996. 
Ahora bien, para determinar cuál sería la extensión (largo y ancho) de una faja fiscal, debemos distinguir dos posibles situaciones que se explicarán a continuación: camino público creado mediante un procedimiento de expropiación; y camino de uso inmemorial.

\section{Origen de un camino: camino público creado mediante un procedimiento de expropiación vs. Camino de uso inmemorial.}

\section{Camino público creado mediante un procedimiento de expropiación}

Para identificarlos, debemos remitirnos al procedimiento de expropiación que dio origen al camino público, el que está normado en el Manual de Carreteras, Volumen No 2, Sección 2.809 Expropiaciones, y dispone que "todo camino debe quedar situado dentro de una faja [fiscal] de terreno de propiedad fiscal"34 (el énfasis es nuestro). En este sentido, la expropiación es definida como "la adquisición del Estado de todas las superficies de terreno de propiedad privada que quedan comprendidos dentro de la futura faja [fiscal] de un camino público" ${ }^{35}$. El documento esencial para la expropiación es el Plano de Expropiaciones, el que debe contener -entre otras indicaciones- "los límites de la Faja Fiscal propuesta a expropiar" 36 , el que deberá incluir también la ubicación de los cercos existentes y presuntos de la faja fiscal.

Así el Manual de Carreteras define a la "Faja del Camino" o Faja Fiscal, como aquella "faja de terreno de propiedad fiscal, en el cual debe quedar comprendida la totalidad de las obras" 37 .

Por consiguiente, la Faja Fiscal consistiría en aquel espacio de terreno ya expropiado ${ }^{38}$ sobre el cual se construirá el nuevo camino, delimitado por los cercos dibujados en el Plano de Expropiación. Una vez finalizada la construcción del camino, la Faja Fiscal corresponderá a la suma de la calzada -vía por donde van los autos-, las bermas y el área donde se podrían ubicar "obras de arte" 39.

\section{Camino de uso inmemorial}

Respecto de estos caminos debemos detenernos en el artículo 26 del DFL 850/1997, según el cual "Todo camino que esté o hubiere estado en uso público se presumirá

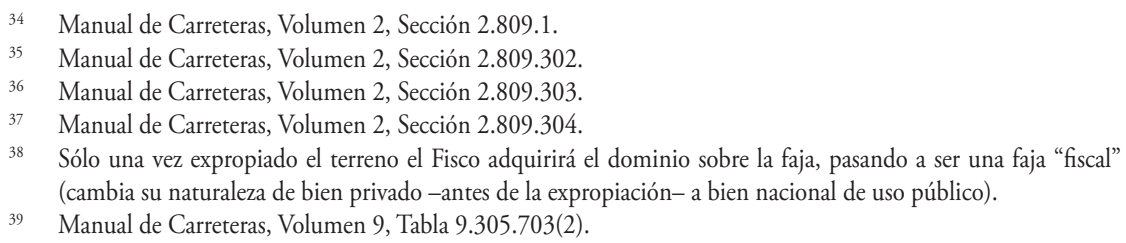


público en todo el ancho que tenga o haya tenido y la Dirección de Vialidad ordenará y hará cumplir su reapertura o ensanche, en caso de haber sido cerrado o modificado, cualquiera que sea el tiempo durante el cual el camino haya permanecido total o parcialmente sustraído al uso público. Esta disposición no excluye el derecho del particular para reclamar judicialmente su dominio".

$\mathrm{Al}$ respecto, cabe hacer presente que en todo tipo de bienes, incluidos los bienes raíces, para tener su posesión y por tanto el dominio, se requiere tener el corpus y el animus. El corpus importa la tenencia material de la propiedad y, en materia de inmuebles, su inscripción en el Conservador de Bienes Raíces competente. Por su parte, el animus es detentar la cosa con ánimo de señor y dueño. Así, el artículo 925 del Código Civil señala que "la posesión del suelo se prueba por hechos positivos, de aquellos a que sólo da derecho el dominio, como el corte de maderas, la construcción de edificios, la de cerramientos, las plantaciones o sementeras, y otros de igual significación, ejecutados sin el consentimiento del que disputa la posesión”. Esta norma viene a establecer la forma en que se determina la posesión de un predio cuando los deslindes consignados en la inscripción son confusos o vagos. En relación a dicho tema, Luis Claro Solar señala lo siguiente: "Las indicaciones de los títulos de propiedad, especialmente tratándose de predios rústicos, son muchas veces vagas o poco precisas y pueden surgir de ello contiendas posesorias entre los vecinos, aunque ambos tengan sus títulos inscritos. En tales casos y en todos aquellos en que se presenten dificultades para la inteligencia de los títulos inscritos, habrá que probar la posesión efectiva del suelo mismo y en tales casos tendrá aplicación el artículo 925 del Código Civil, aun tratándose de cosas inmuebles inscritas (...) ${ }^{\prime 40}$. En el mismo sentido, Fernando Rozas Vial sostiene que este artículo se aplica a los bienes raíces cuyos deslindes aparecen confusos o vagos y no se distingue respecto de la posesión inscrita a favor de otros propietarios ${ }^{41}$.

En consecuencia, respecto de los caminos públicos de uso inmemorial habrá que determinar, caso a caso, quién detentó el bien o cosa (el Fisco o un particular), y quién por sí o por interpósita persona, actuó con ánimo de señor y dueño. En efecto, el artículo 26 del DFL 850/1997 establece una presunción simplemente legal según la cual se presume público y, por ende, de posesión del Fisco, todo el ancho de un camino que esté o hubiese sido de uso público, sin perjuicio del derecho de un particular a probar lo contrario. Así, le corresponderá al particular controvertir lo anterior, probando el corpus y el animus sobre el camino público, o bien sobre una parte del ancho de éste (en caso que no exista claridad sobre los deslindes). 


\section{El caso de los atraviesos y paralelismos en caminos públicos.}

Los atraviesos y paralelismos que, valga la redundancia, atraviesan o van en paralelo a un camino público, se encuentran regulados en el "Instructivo sobre Atraviesos en Caminos Públicos”, y en el "Instructivo sobre Paralelismos en Caminos Públicos”. El primero de éstos especifica “(...) los requisitos a que deberá ceñirse el diseño, cálculo, construcción y mantenimiento de atraviesos en caminos públicos por conductos varios y líneas aéreas" ${ }^{42}$, mientras que el segundo "(...) los requisitos y condiciones a que deberán ceñirse la autorización, diseño, construcción, mantenimiento y operación de los paralelismos en los caminos públicos”³.

\section{Atraviesos sobre caminos públicos.}

El concepto de obra de "atravieso" es definido en artículo 3.1. deI Instructivo sobre Atraviesos en Caminos Públicos como "todas las obras que deben ejecutarse para cruzar un camino público mediante los conductos o postaciones a que se refiere esta Norma”. Por consiguiente, dicho Instructivo regula "los conductos (...) que transportan gases, líquidos o sólidos, que deban mantenerse confinados, ya sea por condiciones de diseño, valor o peligrosidad. A modo de ilustración, se señalan los siguientes fluidos conducidos: agua potable, aguas servidas, desechos industriales, gases y vapores, minerales [y] productos industriales".

Los atraviesos que cruzan caminos públicos son clasificados según sus (a) condiciones de trazado, como (a.i) atraviesos superiores e (a.ii) inferiores, y según la (b) forma del conducto portador, como (b.i) cerrados, (b.ii) abiertos o a tajo abierto, o cuanto (b.iii) líneas o postaciones ${ }^{44}$.

Así, el artículo 5.1.1 de dicho Instructivo especifica que los atraviesos superiores “(...) se diseñarán incluyendo las contravenciones que garanticen rigidez tanto en el plano horizontal como vertical". En este orden de ideas, y a modo de ejemplo, un proyecto de atravieso debería incluir en su diseño contravenciones o elementos de estructuras verticales (los que según el artículo 1.1.2 de la OGUC corresponden a aquellos elementos resistentes u orgánicos de una construcción, como cimientos, pilares, postes, pilotes, torres y otros análogos ${ }^{45}$ ), que soporten aquellos conductos por los cuales podría transportarse fluidos tales como agua potable, aguas servidas, gases y vapores. Igualmente, un proyecto de atravieso podría incluir contravenciones horizontales o vigas, que ayuden a sostener los conductos que atravesarán el camino público.

42 Instructivo sobre Atraviesos en Caminos Públicos, Ministerio de Obras Públicas, Dirección de Vialidad, número 1.2., p. 2.

43 Instructivo sobre Paralelismos en Caminos Públicos, Ministerio de Obras Públicas, Dirección de Vialidad, número 1.1., p. 2.

44 Instructivo sobre Atraviesos en Caminos Públicos, Ministerio de Obras Públicas, Dirección de Vialidad, número 4., p. 3.

45 OGUC: artículo 1.1.2: "Elemento de estructura": todo elemento resistente u orgánico de una construcción, como cimientos, muros soportantes, suelos, pilares, techumbres, torres y otros análogos. 
En este sentido, el artículo 5.2.4 del Instructivo sobre Atraviesos en Caminos Públicos especifica que "el trazado en planta de un atravieso superior será en recta en toda la longitud de la estructura soportante", siendo para el caso la estructura soportante los postes y las vigas.

De este modo, un proyecto de atravieso aéreo consiste en un sistema o conjunto de partes compuesto por postes, vigas y tuberías o conductos, accediendo la estructura soportante a la estructura aérea principal, pudiéndose cimentar su estructura soportante (postes) en la faja de un camino público, para que su estructura aérea principal soporte los conductos o tuberías (que conducirán determinados líquidos) que atravesarán el camino público en cuestión. Al respecto, cabe hace presente que el numeral 6.3. de dicho Instructivo ordena que sólo se autorizarán atraviesos, en la medida que se mantenga “(...) la estabilidad de las obras viales en servicio así como la de las otras instalaciones en la faja del camino" ${ }^{46}$. Con todo, la estructura soportante de un proyecto de atravieso podría cimentarse en un terreno particular contiguo al camino público, caso en el que éste será atravesado únicamente por la estructura superior (independiente de ello, el proyecto de atravieso deberá ser autorizado como un todo, ya que es una sola obra).

Por su parte, el artículo 5.1.2 de dicho Instructivo, define en cuáles casos los atraviesos inferiores deberán efectuarse en conductos cerrados, a tajo abierto, o respecto de líneas. En efecto, para el caso de los atraviesos inferiores cerrados, éstos podrán ser subterráneos y, en casos debidamente calificados, se podrá autorizar para que éstos puedan cruzar caminos públicos "(...) a través de obras de arte o estructuras existentes $(\ldots)^{\text {" }} 7$. Asimismo, “(...) se podrá autorizar que un elemento estructural que forma parte de un puente, de un paso superior o de una estructura afín, sirva de sustento para el atravieso de ductos $(\ldots)^{m 48}$.

\section{Paralelismos en caminos públicos.}

Los paralelismos corresponden a “(...) toda instalación u obra cuya formación, disposición o emplazamiento, requiera ocupar los terrenos de la faja vial [o fiscal] de un camino público, siendo el sentido longitudinal de ella, dentro de sus líneas de cierre o entre las líneas oficiales establecidas por los planes reguladores en el caso de las calles o avenidas declaradas caminos públicos" ${ }^{49}$.

La regulación de los paralelismos es bastante similar a la de los atraviesos (inferiores), por lo que en este caso no ahondaremos mayormente en ella.

46 Instructivo sobre Atraviesos en Caminos Públicos, Ministerio de Obras Públicas, Dirección de Vialidad, número 6.3, p. 9 .

47 Instructivo sobre Atraviesos en Caminos Públicos, Ministerio de Obras Públicas, Dirección de Vialidad, número 5.1.2, p. 4.

48 Ibid.

49 Instructivo sobre Paralelismos en Caminos Públicos, Ministerio de Obras Públicas, Dirección de Vialidad, número 1.2., p. 2. 


\section{Facultad de otorgar permisos y concesiones sobre bienes municipales o nacionales de uso público.}

Los artículos 5 letra c) y 36 de la Ley Orgánica Constitucional de Municipalidades, contenida en el Decreto con Fuerza de Ley No 1, que fija el texto refundido, coordinado y sistematizado de la Ley No 18.695 (la "LOC de Municipalidades"), establecen una regla de "competencia residual" 50 para las Municipalidades, "en el sentido que sólo le corresponde ejercer su administración cuando ésta no ha sido asignada a otro órgano administrativo" ${ }^{51}$. Como se verá a continuación, por regla general, a las Municipalidades les corresponde administrar los bienes nacionales de uso público, incluido su subsuelo.

Pues bien, el artículo 5 letra c) de la LOC de Municipalidades dispone lo siguiente: "Para el cumplimiento de sus funciones las municipalidades tendrán las siguientes atribuciones esenciales: c) Administrar los bienes municipales y nacionales de uso público, incluido su subsuelo, existentes en la comuna, salvo que, en atención a su naturaleza o fines y de conformidad a la ley, la administración de estos últimos corresponda a otros órganos de la Administración del Estado" 52 . En este orden de ideas, el artículo 36 de la LOC de Municipalidades advierte: "Los bienes municipales o nacionales de uso público, incluido su subsuelo, que administre la municipalidad, podrán ser objeto de concesiones y permisos.

Los permisos serán esencialmente precarios y podrán ser modificados o dejados sin efecto, sin derecho a indemnización.

Las concesiones darán derecho al uso preferente del bien concedido en las condiciones que fije la municipalidad. Sin embargo, ésta podrá darles término en cualquier momento, cuando sobrevenga un menoscabo o detrimento grave al uso común o cuando concurran otras razones de interés público.

El concesionario tendrá derecho a indemnización en caso de término anticipado de la concesión, salvo que éste se haya producido por incumplimiento de las obligaciones de aquél" 53 .

Respecto de los permisos municipales, éstos son otorgados directamente por el Alcalde, sin necesidad de contar con la autorización previa del Concejo Municipal (artículo 63 letras f) y j) de la LOC de Municipalidades). Sin embargo, en relación con las concesiones municipales, en virtud de lo dispuesto en el artículo 65 letra j) de la LOC de Municipalidades, el Alcalde necesitará el acuerdo del Concejo Municipal para otorgar concesiones municipales, renovarlas y ponerles término. Otra diferencia, estriba en

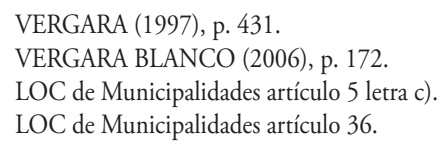


que en el permiso se otorga una autorización de uso especial ${ }^{54}$, mientras que en la concesión dicho uso es privativo ${ }^{55}$.

A cambio de los permisos o concesiones, la Municipalidad podrá cobrar derechos (artículo 5 letra e) y artículo 65 letra c) de la LOC de Municipalidades), correspondiéndole al Alcalde, previo acuerdo del Concejo Municipal (artículo 65 letra k) LOC de Municipalidades) dictar la respectiva ordenanza municipal que establezca la tarifa por los permisos o concesiones, pudiendo efectuar diversas clasificaciones de concesiones y permisos, además de sus respectivas tarifas por éstos ${ }^{56}$. Además, los derechos que la Municipalidad cobre por los permisos o concesiones que haya otorgado constituyen parte del patrimonio de la municipalidad (artículo 13 LOC de Municipalidades). A modo de ejemplo, se puede mencionar una concesión municipal otorgada para la construcción y operación de estacionamientos subterráneos o bien, un permiso para la instalación de un kiosco de revistas sobre una plaza municipal.

Por consiguiente, las municipalidades están facultadas para otorgar concesiones y/o permisos únicamente sobre aquellos bienes nacionales de uso público que se encuentren bajo su administración, pudiendo cobrar derechos por éstos.

Finalmente, un Alcalde sólo podría revocar una concesión otorgada en caso de sobrevenir un menoscabo o detrimento grave al uso común o cuando concurran otras razones de interés público, debiendo contar con el acuerdo previo del Concejo Municipal. En este caso, el concesionario tendrá derecho ser indemnizado, salvo que el término anticipado de la concesión se haya producido por incumplimiento de las obligaciones que éste tenía. Como se verá, un Alcalde podrá otorgar una concesión, previo acuerdo del Concejo Municipal, para usar e instalar un acueducto en parte del subsuelo del cauce de un río, debiendo el solicitante o particular pagar aquellos derechos municipales que se mencionen en la ordenanza municipal respectiva.

\section{Competencia de una municipalidad para administrar una vía urbana.}

De conformidad con la competencia residual de las Municipalidades explicada anteriormente, son éstas las competentes para administrar las vías urbanas (avenidas, calles y pasajes), atendido que éstas son bienes nacionales de uso público. Por lo anterior, para ocupar temporalmente una calle o bien, para instalar una estructura que atraviese una avenida, se deberá solicitar un permiso o concesión a la Municipalidad respectiva.

\footnotetext{
REYES (1960), p. 170 a 175.

REYES (1960), p. 222 y 223.

56 El artículo 12 de la LOC de Municipalidades define a las ordenanzas como aquellas "normas generales y obligatorias aplicables a la comunidad. En ellas podrán establecerse multas para los infractores, cuyo monto no excederá de cinco unidades tributarias mensuales, las que serán aplicadas por los juzgados de policía local correspondientes". Además, las ordenanzas deben ser dictadas por el Alcalde con acuerdo del Concejo, según expresamente lo advierte el literal k) del artículo 65 de la LOC de Municipalidades.
} 


\section{Las aguas en cuanto bien nacional de uso público y su administración.}

El artículo 2 número 34 de la Ley General de Pesca y Acuicultura No 18.982, cuyo texto refundido fue fijado por el Decreto Supremo No 430 de 1991 (la "Ley de Pesca”), establece que una porción de agua corresponde al "espacio de mar, río o lago, destinado a mantener cualquier elemento flotante estable". Por su parte, el artículo 593 del Código Civil define al mar territorial como "el mar adyacente, hasta la distancia de doce millas marinas medidas desde la respectivas líneas de base”. Además, y de conformidad con el artículo 589 del mismo cuerpo legal, el mar territorial (su agua y terreno) corresponde a un bien nacional de uso público. Éste es administrado por la Subsecretaría para las Fuerzas Armadas, en virtud de dispuesto en el artículo 36 de la Ley No 20.424 sobre Estatuto Orgánico del Ministerio de Defensa, y el artículo 2 del DFL No 340 de 1960 sobre Concesiones Marítimas.

Pues bien, de conformidad con los artículos 585 y 595 del Código Civil y el artículo 5 del Código de Aguas, las aguas terrestres son bienes naciones de uso público y se les aplican las normas contendidas en el Código de Aguas ${ }^{57}$, mismo que las clasifica en su artículo 2, a saber:

\section{"Las aguas terrestres son superficiales o subterráneas.}

Son aguas superficiales aquellas que se encuentran naturalmente a la vista del hombre y pueden ser corrientes o detenidas.

Son aguas corrientes las que escurren por cauces naturales o artificiales.

Son aguas detenidas las que están acumuladas en depósitos naturales $o$ artificiales, tales como lagos, lagunas, pantanos, charcas, aguadas, ciénagas, estanques o embalses.

Son aguas subterráneas las que están ocultas en el seno de la tierra y no han sido alumbradas"s8.

Así, los ríos y esteros corresponden a aquellas aguas terrestres, superficiales, corrientes y que escurren por cauces naturales, mientras que los lagos corresponderían a aquellas aguas terrestres, superficiales y las acumuladas en depósitos naturales. Además, de conformidad con el artículo $5^{\circ}$ del Código de Aguas, por regla general ambos tipos de aguas son bienes nacionales de uso público y sobre éstas (corriente y estancada) se pueden otorgar a los particulares el derecho de aprovechamiento de ellas. Sin embargo, podemos encontrar ciertas excepciones, las que se verán a continuación.

Dentro de las aguas corrientes que escurren por cauces naturales existe una hipótesis de "bien privado", como también la existe respecto de las aguas detenidas en depósitos naturales. En efecto, el inciso segundo del artículo 20 del Código de Aguas las exceptúa

57 Código de Aguas, artículo 1.

58 Código de Aguas, artículo 2. 
de ser bienes nacionales de uso público y las define como "las aguas que corresponden a vertientes que nacen, corren y mueren dentro de una misma heredad, como asimismo, sobre las aguas de lagos menores no navegables por buques de más de cien toneladas, de lagunas y pantanos situados dentro de una sola propiedad. (...) Se entiende que mueren dentro de la misma heredad las vertientes o corrientes que permanentemente se extinguen dentro de aquélla sin confundirse con otras aguas, a menos que caigan al mar" ${ }^{2}$. Atendido que son bienes privados, la norma anteriormente referida exceptúa dichas aguas de aquellas respecto de las cuales la autoridad puede conceder derechos de aprovechamiento, otorgándoselas "por el solo ministerio de la ley, al propietario de las riberas". Esto último confirma que estas especies de lagos (o aguas detenidas en general), se tratan de aguas privadas, que pertenecen al propietario del inmueble donde se encuentran éstas ubicadas.

Cabe hacer presente que el órgano encargado de administrar, controlar y fiscalizar los ríos, esteros y lagos (en la medida que éstos sean bienes nacionales de uso público), es la Dirección General de Aguas del Ministerio de Obras Públicas (la "DGA"), según lo advierte el artículo 299 del Código de Aguas ${ }^{60}$. Por ejemplo, es del caso mencionar que en virtud de esta atribución, la DGA dictó la Resolución Exenta No 3504 de 2008, que aprueba el Manual de Normas y Procedimientos para la Administración de Recursos Hídricos.

Por su parte, el artículo 594 del Código Civil concibe las playas de mar como "la extensión de tierra que las olas bañan y desocupan alternativamente hasta donde llegan en las más altas mareas". Éstas son bienes nacionales de uso público ${ }^{61}$ y su administración está entregada a la Subsecretaría para las Fuerzas Armadas, en virtud de dispuesto en el artículo 36 de la Ley No 20.424 sobre Estatuto Orgánico del Ministerio de Defensa, y el artículo 2 del DFL No 340 de 1960 sobre Concesiones Marítimas.

Ahora bien, las llamadas "playas de río o de estero" también pertenecen a la categoría de bienes nacionales de uso público y si bien no están definidas en el Código de Aguas, en diversas normas se hace referencia a ellas ${ }^{62}$. Además, el Código de Aguas no distingue al "álveo, lecho o fondo" del "cauce o playa”. Sin embargo, el Decreto Supremo No 609 de 1979 que "fija normas para establecer deslindes propietarios riberanos con el bien nacional de uso público por las riberas de los ríos" del actual Ministerio de Bienes Nacionales (el "DS 609 de 1979"), distingue y define en su Letra B № 4 al lecho y al cauce de ríos y lagos, a saber:

a) Se considerará lecho o álveo de río, lago o estero, la porción de tierra por la que permanentemente corren las aguas.

\footnotetext{
Código de Aguas, artículo 20.

60 Código de Aguas, artículo 299: "La Dirección General de Aguas tendrá las atribuciones y funciones que este código le confiere, y, en especial, las siguientes: a) Planificar el desarrollo del recurso en las fuentes naturales, con el fin de formular recomendaciones para su aprovechamiento; b) Investigar y medir el recurso (...)".

${ }^{61}$ Código Civil, artículo 589.

62 Por ejemplo, en el artículo 13 del DL 1.939 sobre Adquisición, Administración y Disposición de Bienes del Estado.
} 
b) Se considerará cauce de río, lago o estero la superficie que el agua ocupa y desocupa alternativamente en sus creces periódicas ordinarias.

c) Se considerarán creces extraordinarias, aquellas de rara ocurrencia y que se deban a causas no comunes, producidas sin regularidad, durante períodos, en general, mayores de cinco años. Los terrenos ocupados y desocupados alternativamente en estas creces extraordinarias, no se considerarán cauce de ríos, lagos y esteros y, por tanto, pertenecen a los propietarios riberanos" (el subrayado es nuestro).

Así, las playas de ríos o lagos corresponderían a la definición de cauce, mientras que el fondo de éstos a la de lecho.

En igual sentido, el artículo 2 No 22 de la Ley de Pesca define al lecho o fondo de ríos, lagos y mares como: "Fondo de mar, río o lago: extensión del suelo que se inicia a partir de la línea de más baja marea aguas adentro en el mar, y desde la línea de aguas mínimas en sus bajas normales aguas adentro en ríos o lagos".

No obstante, el Código de Aguas no distingue al "lecho o fondo" del "cauce o playa", sino que en sus artículos 30 y 35 suma ambas tipologías en un mismo y único concepto, al que llama de manera indistinta lecho, cauce o álveo, a saber:

"Artículo 30- Álveo o cauce natural de una corriente de uso público es el suelo que el agua ocupa y desocupa alternativamente en sus creces y bajas periódicas.

Este suelo es de dominio público y no accede mientras tanto a las heredades contiguas, pero los propietarios riberanos podrán aprovechar y cultivar ese suelo en las épocas en que no estuviere ocupado por las aguas".

"Articulo 350- Álveo o lecho de los lagos, lagunas, pantanos y demás aguas detenidas, es el suelo que ellas ocupan en su mayor altura ordinaria. Este suelo es de dominio privado, salvo cuando se trate de lagos navegables por buques de más de cien toneladas".

Con todo, y en relación a los ríos, cabe recordar que no son bienes nacionales de uso público aquellas vertientes que nacen, corren y mueren en un mismo predio, según lo establece el artículo del Código de Aguas. Asimismo, y en relación a los lagos, no tienen la naturaleza de bienes nacionales de uso público aquellos lagos que no son navegables por buques de más de cien toneladas.

Por consiguiente, tanto las aguas como el lecho y el cauce de un río o estero son bienes nacionales de uso público.

Ahora bien, la administración de los Cauces y fondos de ríos y lagos navegables por buques de más de cien toneladas le corresponde a la Subsecretaría para las Fuerzas Armadas, en virtud de lo dispuesto en el artículo 1 del DFL No 340 de 1960 sobre 
Concesiones Marítimas ${ }^{63}$, en relación con el artículo 36 de la Ley No 20.424 sobre Estatuto Orgánico del Ministerio de Defensa. Sin embargo, y de conformidad con el ya mencionado artículo 35 del Código de Aguas, respecto a aquellos lagos que no sean navegables por buques de más de 100 toneladas, atendida su calidad de bien privado, le corresponde al dueño del predio ribereño su administración.

Finalmente, respecto de ríos no navegables por buques de más de 100 toneladas, "su administración está a cargo de las Municipalidades, en virtud de la competencia residual" ${ }^{64}$ establecida en los artículos 5 letra c) y 36 de la LOC de Municipalidades.

Por ende, todo río o estero no navegable por buques de más de 100 toneladas, será el Alcalde la autoridad competente para administrar su lecho y cauce, pudiendo otorgar una concesión para el uso del subsuelo del río o estero. En vista de ello, podrá otorgar una concesión, previo acuerdo del Concejo Municipal, para usar e instalar en parte del subsuelo del lecho y cauce del río o estero un acueducto, debiendo el solicitante o particular pagar aquellos derechos municipales que se mencionen en la ordenanza municipal respectiva.

\section{Importancia de determinar los deslindes de un río o estero: el rol del ministerio de bienes nacionales.}

Para solicitar una concesión para instalar un acueducto bajo el lecho y cauce de un río o estero será de suma relevancia tener certeza de la ubicación de sus deslindes, ya que sólo en la medida que el acueducto esté ubicado dentro de los deslindes de dicho estero, el Alcalde (previo acuerdo del Concejo Municipal) será la autoridad competente para autorizar su instalación.

Al respecto, el ya mencionado DS 609 de 1979 le otorga competencia al Ministerio de Bienes Nacionales para que éste fije a través de un decreto supremo, "los deslindes de los bienes nacionales de uso público que constituyen los Cauces de los ríos, lagos y

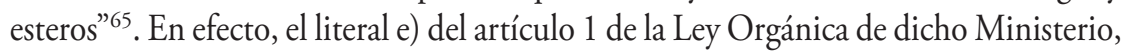
reafirma dicha potestad ${ }^{66}$.

Pues bien, el DS 609 de 1979 dispone en su Letra B No 1 a 3 que:

63 DFL No 340, artículo 1: "Al Ministerio de Defensa Nacional, Subsecretaría de Marina, corresponde el control, fiscalización y supervigilancia de toda la costa y mar territorial de la República y de los ríos y lagos que son navegables por buques de más de 100 toneladas".

64 VERGARA (1997), p. 431.

65 DS 609 de 1979 , Letra B, No 1.

66 Ley Orgánica del Ministerio de Bienes Nacionales, contenida en el Decreto Ley 3274 de 1980. Artículo 1 letra e): "El Ministerio de Bienes Nacionales es la Secretaría de Estado encargada de aplicar, controlar y orientar las políticas aprobadas por el Supremo Gobierno, como asimismo aplicar la legislación correspondiente y controlar su cumplimiento, en las siguientes materias; sin perjuicio de las facultades de la Contraloría General de la República: e) Las demás a que se refieran otras disposiciones legales y reglamentarias". 
“B) 1. Corresponderá al Ministerio de Tierras y Colonización, fijar los deslindes de los bienes nacionales de uso público que constituyen los cauces de los ríos, lagos y esteros, conforme al procedimiento que se señala en los números siguientes.

2. Para la fijación de los deslindes indicados se oirá previamente al Departamento de Defensas Fluviales de la Dirección General de Obras Públicas, quien informará sobre la materia y agregará a su informe técnico un plano de la zona del río, lago o estero cuyo deslinde se trata de fijar, indicando dicho deslinde.

3. El Ministerio de Tierras y Colonización fijará por un decreto supremo los deslindes de los cauces de los ríos, lagos y esteros, de oficio cuando las circunstancias así lo exigieren o a petición del propietario riberano cuando éste lo solicite, en ejercicio del derecho que le otorga el artículo $842^{\circ}$ del Código Civil”.

La referencia efectuada al Departamento de Defensas Fluviales de la Dirección General de Obras Públicas, debe ser entendida en la actualidad al Director General de Obras Públicas, cuestión que expresamente advierte el inciso tercero de la letra l) del artículo 14 del DFL 850/1997, según la cual le corresponderá al Director General de Obras Públicas: "l) Asimismo, le compete indicar los deslindes de los cauces naturales con los particulares ribereños para los efectos de la dictación por el Ministerio de Bienes Nacionales del decreto supremo correspondiente". La razón de ello, estimamos, estribaría en que siendo competente el Director General de Obras Públicas de construir y conservar las obras de defensa fluviales ${ }^{67}$, debe ser éste quien, asimismo, le indique al Ministerio de Bienes Nacionales los deslindes de los Cauces naturales.

De este modo, ya sea de oficio o a petición de un propietario ribereño, al Ministerio de Bienes Nacionales le corresponde fijar los deslindes del estero o río, debiendo escuchar previamente al Director General de Obras Públicas, quien le indicará los deslindes del cauce respectivo.

\section{Caminos públicos que deslindan con playa de mar o bien, con terrenos de playa.}

$\mathrm{Al}$ respecto, nos detendremos en analizar el caso que un camino público deslinde con una playa de mar o con un terreno de playa. Como se mencionó anteriormente, el artículo 589 del Código Civil advierte que las playas de mar son bienes nacionales de uso público. Por su parte, el artículo 1 No 38 del Reglamento sobre Concesiones Marinas (Decreto Supremo No 2 de 2005, Ministerio de Defensa) define al terreno de playa ${ }^{68}$ como aquella "faja de terreno de propiedad del Fisco sometida al control,

67 DFL No 850 de 1997, artículo 14 l) inciso primero: Al Director General de Obras Públicas corresponderá: "l) El estudio, proyección, construcción y conservación de las obras de defensa de terrenos y poblaciones contra crecidas de corrientes de agua y regularización de las riberas y cauces de los ríos, lagunas y esteros".

68 Hacemos presente que el terreno de playa fiscal no es un bien nacional de uso público, sino que es un bien fiscal (estos últimos pueden o no estar inscritos en el Conservador de Bienes Raíces a nombre del Fisco, según 
fiscalización y supervigilancia del Ministerio, de hasta 80 metros de ancho, medida desde la línea de la playa de la costa del litoral (...)". De este modo, en virtud de dicha definición legal, el artículo 589 del Código Civil y lo expuesto en el numeral 1. anterior, los terrenos de playa son bienes fiscales o bienes del Estado, atendido que son de propiedad del Fisco.

Pues bien, en los hechos podemos tener las siguientes combinaciones, dependiendo de los accidentes geográficos del sector o terreno en cuestión: (a) un mar sin playa de mar (mar que deslinda con un acantilado); (b) un mar con playa de mar, pero sin terreno de playa (mar que deslinda con playa de mar, y ésta a su vez deslinda con, por ejemplo, un inmueble privado o un camino); (c) mar con playa de mar y terreno de playa (mar que deslinda con playa de mar, ésta a su vez deslinda con un terreno de playa que puede llegar a medir hasta 80 metros). En el último caso, el terreno de playa se extenderá hasta que deslinde con, por ejemplo, un predio privado o un camino. Por lo tanto, un camino público podría deslindar con una playa de mar o bien, con un terreno de playa, dependiendo del caso concreto. Esta distinción será relevante al momento de distinguir quién será la autoridad competente para autorizar la instalación de determinadas obras de arte (atravieso o paralelismos) en la faja de un camino o bien, en un terreno de playa o playa de mar.

\section{Conclusiones.}

1. El artículo 19 № 23 garantiza, como regla general, la libre apropiabilidad de los bienes.

2. Dicha regla tiene dos excepciones: (i) aquellos bienes que la naturaleza ha hecho comunes a todos los hombres, vale decir, bienes inapropiables; y (ii) aquellos bienes que deban pertenecer a la Nación toda y la ley lo declare así, es decir, bienes nacionales.

3. Los bienes nacionales pueden ser clasificados como (i) bienes nacionales de uso público o bienes públicos; y (ii) bienes fiscales o bienes del Estado.

4. Las vías urbanas y los caminos públicos son bienes nacionales de uso público.

5. La faja fiscal de todo camino público es administrada por la Dirección de Vialidad del MOP.

6. Las calles (vías urbanas) son administradas por la Municipalidad respectiva.

7. Los caminos públicos corresponden a aquellas vías ubicadas fuera del límite urbano, vale decir, en áreas rurales. Asimismo, una vía urbana pasa a ser camino público, en la medida que un decreto supremo le otorgue tal calidad.

lo dispuesto en el artículo 590 del Código Civil). 
8. Las vías urbanas son aquellas que se encuentran dentro de los límites urbanos, esto es, en un área urbana. Sin embargo, una vía urbana pasa a tener la calidad de un camino público, en la medida que un Decreto Supremo así lo declare.

9. La faja fiscal de un camino público corresponde a todo el ancho que tenga o haya tenido la vía, esto es, (i) aquel espacio que fue expropiado y sobre el cual se construyó el camino público, delimitado por los cercos dibujados en el Plano de Expropiación; o bien, (ii) todo el ancho de la faja fiscal que va de cierre a cierre, esto es, la suma de la calzada -vía por donde circulan los vehículos-, las bermas y el área baldía donde se pueden cimentar las estructuras soportantes de los atraviesos aéreos, y donde se pueden ubicar los atraviesos inferiores o los paralelismos.

10. Quien otorga la autorización para la construcción e instalación de un proyecto de atravieso o paralelismo es la Dirección de Vialidad, atendido que dicho organismo es el competente y encargado de administrar las fajas de los caminos públicos.

11. Las municipalidades, en virtud de su competencia residual, están facultadas para otorgar concesiones y/o permisos únicamente sobre aquellos bienes municipales o nacionales de uso público que se encuentran bajo su administración, siempre y cuando cuenten con el acuerdo previo del Concejo Municipal.

12. Las municipalidades pueden cobrar derechos por las concesiones y/o permisos que otorguen, los que deberán estar tarifados en la respectiva Ordenanza Municipal.

13. El Alcalde, previo acuerdo del Concejo Municipal, puede dar en concesión aquellos bienes naciones de uso público que se encuentren bajo su administración, como lo es el subsuelo de un río o estero no navegable por un buque de más de 100 toneladas.

14. Para instalar un acueducto en el subsuelo del lecho o cauce de un estero o río no navegable por un buque de más de 100 toneladas, se deberá pedir una concesión (previo acuerdo del Concejo Municipal) o un permiso al Alcalde, debiendo pagar el interesado los derechos que la ordenanza indique. La Municipalidad sólo será competente en la medida que el acueducto esté dentro de los deslindes del estero o río, el que debe incluir tanto el lecho como el cauce del mismo.

15. La fijación de los deslindes del estero o río es una atribución exclusiva del Ministerio de Bienes Nacionales, quien podrá fijarlos de oficio o a petición de un propietario ribereño, y los determinará a través de un decreto supremo.

16. No obstante, quien le indicará previamente al Ministerio de Bienes Nacionales los deslindes del estero o río será el Director General de Obras Públicas, en su calidad de autoridad responsable de construir y conservar las obras de defensa fluviales. 


\section{Referencias Bibliográficas.}

ALESSANDRI RODRÍGUEZ, Arturo (1937): Derecho civil:primer año (segundo tomo). De los bienes: versiones taquigráficas tomadas en la clase de derecho civil del señor Arturo Alessandri Rodríguez, Editorial Zamorano y Caperán, Santiago, 330 pp.

CLARO SOLAR, Luis. Explicaciones de Derecho Civil Chileno y Comparado. Volumen III de los Bienes, Tomo Séptimo, Editorial Jurídica de Chile, Santiago, 1979, 606 pp.

MONTT OYARZÚN, Santiago (2002): El Dominio Público: estudio de su régimen especial de protección y utilización, Editorial ConoSur LexisNexis Chile, Santiago, 421 pp.

PEÑAILILLO ARÉVALO, Daniel (2006): Los Bienes, La propiedad y otros derechos reales, Editorial Jurídica de Chile, Santiago, 259 pp.

ROZAS VIAL, Fernando (1984): Derecho Civil. Los Bienes, Editorial Distribuidora Forense Limitada, Santiago, 469 pp.

VERGARA BLANCO, Alejandro (1997): "Tres Problemas Actuales sobre Bienes Nacionales del Dominio Público", en: Revista de Derecho de la U. Católica de Valparaíso XVIII, pp. 423-434.

REYES RIVEROS, Jorge (1960): Naturaleza Jurídica del Permiso y de la Concesión sobre Bienes Nacionales de Uso Público, Editorial Jurídica de Chile, Santiago, 364 pp.

VERGARA BLANCO, Alejandro (2006): "Competencia Administrativa para Autorizar el Uso y Construcción de Obras Hidráulicas en Cauces Naturales”, en: Revista de Derecho Administrativo Económico No 16, pp. 167-178.

\section{Normas citadas.}

Código Civil.

Código de Aguas.

Ley General de Urbanismo y Construcciones (LGUC).

DFL 850 de 1997, que fija el texto refundido, coordinado y sistematizado de la LOC MOP y de la Ley de Caminos (DFL 850/1997).

Ley Orgánica Constitucional de Municipalidades, contenida en el Decreto con Fuerza de Ley No 1, que fija el texto refundido, coordinado y sistematizado de la Ley No 18.695 (LOC de Municipalidades).

Ley General de Pesca y Acuicultura No 18.982, cuyo texto refundido fue fijado por el Decreto Supremo No 430 de 1991 (Ley de Pesca).

Ley No 20.424 sobre Estatuto Orgánico del Ministerio de Defensa.

Ley Orgánica del Ministerio de Bienes Nacionales, contenida en el Decreto Ley 3274 de 1980.

DFL No 340 de 1960 sobre Concesiones Marítimas.

Ordenanza General de Urbanismo y Construcciones (OGUC). 
Decreto Supremo No 609 de 1979, que fija normas para establecer deslindes propietarios riberanos con el bien nacional de uso público por las riberas de los ríos, del actual Ministerio de Bienes Nacionales (DS 609 de 1979).

Plan Regulador Metropolitano de Santiago de 1994 (PRMS).

Circular Específica No 10/2009, Circular Ordinaria No 368, DDU MINVU.

Circular Específica No 3/2010, Circular Ordinaria No 148, DDU MINVU.

Manual de Carreteras, Volúmenes 2 y 9, MOP.

Instructivo sobre Atraviesos en Caminos Públicos, Ministerio de Obras Públicas, Dirección de Vialidad, 2006.

Instructivo sobre Paralelismos en Caminos Públicos, Ministerio de Obras Públicas, Dirección de Vialidad, 2006.

\section{Sentencias citadas}

Sentencia Tribunal Constitucional Rol No 1281-2009, de 13 de agosto de 2009. Requerimiento de inaplicabilidad por inconstitucionalidad, respecto del artículo 459 No 1 del Código Penal, sobre usurpación de aguas subterráneas. 